\title{
Alcohol Exposures, Alcohol Marketing, and Their Associations with Problem Drinking and Drunkenness among Youth Living in the Slums of Kampala, Uganda
}

\author{
Monica H. Swahn, ${ }^{1}$ Jane B. Palmier, ${ }^{1}$ and Rogers Kasirye ${ }^{2}$ \\ ${ }^{1}$ Institute of Public Health, Georgia State University, P.O. Box 3995, Atlanta, Georgia, GA 30302-3995, USA \\ ${ }^{2}$ Uganda Youth Development Link, Kampala, Uganda \\ Correspondence should be addressed to Monica H. Swahn; mswahn@gsu.edu
}

Received 11 March 2013; Accepted 8 April 2013

Academic Editors: J. Klewer, S. M. Pezzotto, K. M. Rospenda, and O. Zurriaga

Copyright (C) 2013 Monica H. Swahn et al. This is an open access article distributed under the Creative Commons Attribution License, which permits unrestricted use, distribution, and reproduction in any medium, provided the original work is properly cited.

\begin{abstract}
This study determined the associations between alcohol use exposures, marketing, education, and problem drinking and drunkenness among youth living in the slums of Kampala. This cross-sectional study of youth was conducted in 2011 to quantify and describe high-risk behavior and exposures in a convenience sample $(N=457)$ of urban youth living in the slums, 14-24 years of age, who were participating in a drop-in center for disadvantaged street youth. Logistic regression analyses were computed to determine associations between alcohol use exposures, marketing exposures, alcohol education, and problem drinking and drunkenness while controlling for possible confounders. Among participants, 30.2\% reported problem drinking and 32.8\% reported drunkenness. In multivariate analyses, obtaining free drinks was associated with problem drinking (AOR: $2.47 ; 95 \% \mathrm{CI}=1.23-4.96$ ) and drunkenness (AOR: 2.40; 95\% CI $=1.22-4.70$ ) after controlling for potential confounders. Alcohol education measures were not significantly associated with either problem drinking or drunkenness in multivariate analyses. There are important associations between alcohol marketing and drinking among these youth. Moreover, the findings underscore the need for additional research related to the impact of alcohol marketing among vulnerable youth and also the need for policy regulations that restrict alcohol marketing that involve providing free alcohol directly to youth.
\end{abstract}

\section{Introduction}

Alcohol use is the most commonly used psychoactive substance in the world and is one of the leading causes of death and disability worldwide [1]. Alcohol abuse causes $3.2 \%$ (1.8 million) of all deaths worldwide annually and also accounts for $4.0 \%$ of the global disease burden each year [2]. Research has shown that alcohol use is associated with alcohol addiction [3], other drug use [4], unintentional injuries [5, 6], physical fighting [7], criminal activity [4], suicidal ideation and attempts [8-10], and increased risk of human immunodeficiency disease (HIV) [11, 12].

In order to address this global public health issue, the World Health Organization (WHO) recently prioritized the global reduction of the harmful use of alcohol with a particular focus on monitoring and technical support [13].
Even with limited data, it is still evident that low-income and middle-income countries, and vulnerable populations within, bear an increased burden of disease and injury due to increasing alcohol consumption and limited or nonexistent public health and prevention policies and programs [1]. In sub-Saharan Africa, alcohol use has been found to be associated with early alcohol use [14], risky unprotected sex [15-18], mental disorders [19], and road traffic accidents and injuries [20].

Alcohol use is affected by a range of individual and environmental factors as well as attitudes toward alcohol use, perceived susceptibility of alcohol use, peer drinking, accessibility of alcohol, and exposure to either antialcohol campaigns or to alcohol advertising as well as ownership of alcohol promotional items [21-26]. An empirical review of research in sub-Saharan Africa also demonstrated that 
alcohol use and risky sexual behavior are linked to drinking venues and alcohol serving establishments [16]. In Uganda, for example, alcohol use among youth has been found to be significantly associated with both suicide ideation and physical fighting [27]. However, research on the correlates and predictors of alcohol use and its adverse outcomes among youth is relatively scarce in sub-Saharan Africa.

An important and previously largely unaddressed issue in sub-Saharan Africa is the role of alcohol marketing and its potential link to alcohol use among youth. In one of the few empirical studies conducted on alcohol marketing in subSaharan Africa, findings demonstrate that alcohol marketing, specifically through the provision of free alcohol to schoolattending youth (primarily ages 13-15), is relatively common in Zambia (30\%) and that this form of marketing is associated with problem drinking and drunkenness [26]. Although a previous project by the WHO outlines some key issues related to marketing from a qualitative perspective based on focus groups of youth in Uganda, Gambia, Ghana, and Nigeria [28], there is a dearth of empirical information about alcohol marketing practices and their influence specifically on youth in sub-Saharan Africa. The lack of empirical research in Uganda is specifically troubling since it has one of the highest estimated alcohol per capita consumption worldwide [2].

Previous research conducted primarily in North America and Europe shows that exposure to alcohol advertising and ownership of alcohol promotional items has been found to increase the risk of alcohol use among adolescents [22, 29]. Moreover, based on extensive research, it is clear that alcohol marketing also influences youths' attitudes and perceptions about alcohol, which are related to expectancies and intentions to consume alcohol beverages [30, 31]. Relatedly, youth who report liking alcohol advertisements are also more likely to use alcohol $[32,33]$. More troubling perhaps is also the issue of the long-lasting effect of alcohol marketing exposure. Research shows that exposure to alcohol advertising in youth predicts youth's intentions of alcohol consumption up to two years later [34]. Additionally, ownership of alcohol-branded merchandise has been associated with a range of high-risk behavior, poor academic performance, and early alcohol use initiation among youth [23].

The totality of previous research indicates that alcohol marketing to youth is a growing public health concern [35-37] and that this problem may be exacerbated among youth living in countries with limited alcohol policies and that rely on self-regulation by the alcohol industry [3537]. This may be the case because of the resources available to the alcohol industry for their marketing efforts. Alcohol Justice (formerly the Marin Institute) is a group dedicated to respond to the alcohol industry and their marketing practices primarily in USA. They report that the alcohol industry spends more than $\$ 6$ billion each year on marketing its products [38]. Unfortunately, many alcohol marketing practices are aimed directly at youth [35-37] and those that are outside of the home (e.g., billboards, advertisements on public transit vehicles, buildings, newspaper stands and kiosks, and Internet) pose particular concerns because parents cannot typically shield their children from those exposures. However, spending on these forms of marketing, labeled "out-of-home advertising" has increased more than $\$ 2$ billion over the past three years by major alcohol companies [34]. Alcohol advertising and marketing of alcohol products clearly increase intent to use as well as actual alcohol use among adolescents $[30,31,33,34]$. However, there is a dearth of information about alcohol marketing practices and their influence specifically on youth in sub-Saharan Africa even though alcohol marketing in many countries in this region appears common and is perhaps also increasing in scope.

The purpose of this study is to examine the prevalence of alcohol marketing and alcohol education exposure in a convenience sample of youth who live in the slums of Kampala, Uganda. Moreover, the study examines if there are significant associations between alcohol marketing and alcohol education and heavy alcohol use including drunkenness and problem drinking among these Ugandan youth who mostly do not attend school. One previous study of a large sample of school-attending youth in Zambia indicates that alcohol marketing is an important concern in that country and that exposure to alcohol marketing there is associated with problem drinking and drunkenness [26]. Thus, this study will seek to replicate those findings in a study of primarily non-school-attending youth in Kampala to determine the generalizability of the findings and to also report on alcohol knowledge skills and behavior that may buffer the potential impact of alcohol marketing on alcohol use. The findings from this study will be important for prevention efforts that seek to reduce alcohol use among youth and to inform both future research and practice.

\section{Methods}

The overarching goal of the cross-sectional survey called the "Kampala Youth Survey," conducted in May and June 2011, was to assess a range of health risk behavior and exposures including alcohol marketing and its associations with problem drinking and drunkenness in a convenience sample of urban youth living in the slums and who were between 14 and 24 years of age. The methodology and findings from this study have been reported previously [39, 40]. Briefly, the youth participants were receiving services in a Uganda Youth Development Link (UYDEL) [41] drop-in center for disadvantaged street youth. UYDEL serves on average about 650 youth per month through these drop-in centers. Faceto-face surveys, lasting about 30 minutes, were administered by social workers/peer educators employed by UYDEL. The study was implemented across 8 drop-in centers across Kampala. Participating youth received snacks and transportation for completing the survey. No identifying information was collected and the surveys were completely anonymous. Surveys were administered in English or Luganda (local language), to the extent possible, in private settings and rooms, to ensure privacy of survey questions and responses. Each social worker/peer educator received training on the study methodology, each of the survey questions and its translation into Luganda if needed, and recruited potential 
TABle 1: Variable name, description, and prevalence of factors examined in the Kampala youth survey $(N=457)$.

\begin{tabular}{|c|c|c|}
\hline Variable name & Variable description & $N=457$ \\
\hline Sex & Percentage of participants who were girls. & $68.5 \%$ \\
\hline Current alcohol use & $\begin{array}{l}\text { Percentage of youth who had at least one drink containing alcohol on one or more } \\
\text { days during the past } 30 \text { days. }\end{array}$ & $30.0 \%$ \\
\hline Problem drinking & $\begin{array}{l}\text { Percentage of youth who ever had a hangover, felt sick, got into trouble with family or } \\
\text { friends, missed school, or got into fights, as a result of drinking alcohol. }\end{array}$ & $30.2 \%$ \\
\hline Drunkenness & Percentage of youth who drank so much alcohol that they were really drunk. & $32.8 \%$ \\
\hline Sadness & $\begin{array}{l}\text { Percentage of youth who felt so sad or hopeless almost every day for two weeks or } \\
\text { more in a row that they stopped doing their usual activities during the past } 12 \text { months. }\end{array}$ & $77.1 \%$ \\
\hline No friends & Percentage of youth who have no close friends. & $9.5 \%$ \\
\hline Illicit drug use & Percentage of youth who used drugs during their life. ${ }^{1}$ & $13.8 \%$ \\
\hline Violence victimization & $\begin{array}{l}\text { Percentage of youth who reported being threatened or injured with a weapon, such as } \\
\text { a gun, knife, or club. }\end{array}$ & $35.5 \%$ \\
\hline HIV/AIDS & $\begin{array}{l}\text { Percentage of youth who have been told by a doctor or nurse that they have } \\
\text { HIV/AIDS (yes versus no). }\end{array}$ & $8.4 \%$ \\
\hline Alcohol use and marketing exposure & $\begin{array}{l}\text { Percentage of youth reporting 5-6 types of alcohol use and marketing exposures (i.e. } \\
\text { seeing actors drink on TV, seeing brand names on TV, seeing ads in magazines, } \\
\text { seeing ads in the city, seeing billboards with alcohol ads in the city, and seeing people } \\
\text { drink in the city). }\end{array}$ & $62.1 \%$ \\
\hline Alcohol marketing & & - \\
\hline Brand logo & $\begin{array}{l}\text { Percentage of youth who have a t-shirt, pen, backpack, or other item, with an alcohol } \\
\text { brand logo on it. }\end{array}$ & $25.9 \%$ \\
\hline Provided free alcohol & $\begin{array}{l}\text { Percentage of youth who were ever offered a free drink of alcohol by an alcohol } \\
\text { company representative. }\end{array}$ & $27.0 \%$ \\
\hline Alcohol education & & - \\
\hline Danger of alcohol & Percentage of youth who were taught the dangers of alcohol use. & $89.2 \%$ \\
\hline Help quit & $\begin{array}{l}\text { Percentage of youth who have ever been told where to get help to stop drinking } \\
\text { alcohol. }\end{array}$ & $72.4 \%$ \\
\hline Refuse alcohol & $\begin{array}{l}\text { Percentage of youth who were taught to tell someone they did not want to drink } \\
\text { alcohol. }\end{array}$ & $74.7 \%$ \\
\hline
\end{tabular}

${ }^{1}$ The types of drugs included in the question were marijuana ("njaga or bangi"), opium ("njaye"), or aviation fuel.

participants among attendants at their specific drop-in center. Recruitment took place using word-of-mouth, and each attendant was eligible for participation if they were between 14 and 24 years of age. No exclusion criteria were applied beyond the age range. Participants were informed about the study and read (or were read) the consent forms to indicate their willingness to take the survey. The consent process required that emancipated street youth from 14 to 17 years of age provide their own consent for participating in the survey. (Because youth from 14 to 17 years of age who "cater for their own livelihood" are considered emancipated in Uganda, parental permission/consent had been waived.) The same consenting process was followed for youth from 18 to 24 years of age.

Over the ten-day survey period, 507 youth were approached for participating in the survey. Among these youth, 46 declined and 461 agreed to participate, yielding a participation rate of $90.9 \%$. Four of the surveys were missing substantial numbers of responses and were therefore excluded, yielding 457 completed surveys for the final analytic sample of youth between the ages of 14 and $24(31 \%$ boys and $69 \%$ girls). The mode for age was 17 years $(n=81)$ and $67 \%$ of participants were between ages 16 and 20 .

\section{Measures}

The questionnaire was modeled from existing surveys such as the U.S. based Youth Risk Behavior Survey [42] conducted by the Centers for Disease Control and Prevention and the International Global School-Based Student Health Survey [43] supported by the World Health Organization and which provides data on health behavior and relevant risk and protective factors among students across all regions served by the United Nations. Survey questions addressed demographic characteristics, family context, alcohol and drug use, injuries, violence and suicidal behavior, sexual behavior, and sexually transmitted diseases, including HIV/AIDS.

\section{Analysis}

The measures included in the analyses and their prevalence among study participants are described in Table 1. Bivariate and multivariate logistic regression analyses were computed to determine statistical association between alcohol marketing exposures, alcohol education, and drunkenness and problem drinking (demographic and psychosocial correlates) 
TABLE 2: Bivariate associations between demographic characteristics, alcohol marketing, and alcohol education, and problem drinking and drunkenness among participants in the Kampala Youth Survey $(N=457)$.

\begin{tabular}{|c|c|c|c|c|c|c|}
\hline \multirow{2}{*}{ Variables } & \multicolumn{2}{|c|}{ Current alcohol } & \multicolumn{2}{|c|}{ Problem drinking } & \multicolumn{2}{|c|}{ Drunkenness } \\
\hline & $\%$ & OR $(95 \% \mathrm{CI})$ & $\%$ & OR $(95 \% \mathrm{CI})$ & $\%$ & OR $(95 \% \mathrm{CI})$ \\
\hline \multicolumn{7}{|l|}{ Sex } \\
\hline Boys & 39.01 & $1.83(1.20-2.80)$ & 31.21 & $1.95(1.23-3.07)$ & 33.57 & $2.00(1.28-3.13)$ \\
\hline Girls & 25.88 & 1.00 & 18.91 & 1.00 & 20.19 & 1.00 \\
\hline \multicolumn{7}{|l|}{ Age } \\
\hline$\geq 18$ & 39.85 & $3.13(2.00-4.91)$ & 30.77 & $3.27(1.96-5.44)$ & 31.27 & $2.56(1.59-4.12)$ \\
\hline$<18$ & 17.19 & 1.00 & 11.98 & 1.00 & 15.10 & 1.00 \\
\hline \multicolumn{7}{|c|}{ Alcohol use and marketing exposure } \\
\hline $0-4$ & 13.92 & 1.00 & 11.39 & 1.00 & 10.13 & 1.00 \\
\hline $5-6$ & 33.43 & $3.49(1.79-6.83)$ & 24.93 & $2.58(1.24-5.40)$ & 27.22 & $3.70(1.72-7.96)$ \\
\hline \multicolumn{7}{|l|}{ Alcohol marketing } \\
\hline Free drink & 64.46 & $8.33(5.22-13.31)$ & 52.07 & $7.85(4.82-12.79)$ & 53.78 & $7.18(4.45-11.59)$ \\
\hline Brand logo & 60.68 & $6.34(4.00-10.04)$ & 49.57 & $6.36(3.93-10.29)$ & 51.30 & $5.91(3.68-9.49)$ \\
\hline \multicolumn{7}{|l|}{ Alcohol education } \\
\hline Danger of alcohol & 30.02 & $0.97(0.51-1.86)$ & 22.14 & $0.79(0.40-1.55)$ & 23.69 & $0.78(0.40-1.51)$ \\
\hline Help quit & 28.18 & $0.73(0.47-1.13)$ & 21.52 & $0.80(0.49-1.29)$ & 23.78 & $0.92(0.57-1.48)$ \\
\hline Refuse alcohol & 26.84 & $0.55(0.35-0.86)$ & 20.94 & $0.68(0.42-1.10)$ & 22.26 & $0.65(0.41-1.05)$ \\
\hline
\end{tabular}

using the SAS 9.2 and SUDAAN 10 statistical software packages. The associations between alcohol use and marketing exposures for each problem drinking and drunkenness were assessed using a 4-model building approach while controlling for a range of potential confounders. Moreover, all variables were dichotomized to indicate the presence or absence of the particular risk factor. The reference category for each variable in the logistic regression analyses was the absence of the particular risk factor.

\section{Results}

Among participants, 30.2\% reported problem drinking and $32.8 \%$ reported drunkenness. In addition, $62.1 \%$ of the youth reported alcohol marketing exposure, $26.0 \%$ had received an item with an alcohol marketing brand logo, and $27.0 \%$ were ever offered a free drink of alcohol by an alcohol company representative. Moreover, $89.2 \%$ of youth also reported being taught the danger or alcohol use and $74.7 \%$ were taught to tell someone that they did not want to drink alcohol.

The bivariate associations between sex, age, alcohol marketing, and alcohol education and current alcohol use, problem drinking, and drunkenness are presented in Table 2. Boys were more likely than girls to report current alcohol use, drunkenness, or problem drinking. Youth 18 years of age or older were also more likely to report alcohol use, drunkenness, or problem drinking. Alcohol marketing exposure was significantly associated with alcohol use, problem drinking, and drunkenness. Additionally, being offered free drinks through an alcohol company representative was significantly associated with reports of current alcohol use (OR: 8.33; 95\% $\mathrm{CI}=5.22-13.31$ ), problem drinking (OR: 7.85, 95\% CI $=4.82$, 12.79), and drunkenness (OR: 7.18; 95\% CI = 4.45-11.59).
Alcohol marketing through receipt of brand logo items was significantly associated with reports of current alcohol use (OR: 6.34; 95\% CI = 4.00-10.04), problem drinking (OR: 6.36; 95\% CI = 3.93-10.29), and drunkenness (OR: 5.91; $95 \%$ CI $=3.68-9.49)$. Having received alcohol education that taught how to refuse alcohol was inversely associated with reports of current alcohol use, but did not affect reports of problem drinking and drunkenness. Alcohol education that addressed the danger of alcohol or that offered help to quit was not significantly associated with current alcohol use, problem drinking, or drunkenness (Table 2).

Multivariate analyses, presented in Table 3, show that age $(\geq 18)$ was the most consistent correlate of drunkenness across the four models computed. In Models 2 through 4, other drug use was also strongly associated with drunkenness. In Model 3 , which examined the potential role of alcohol marketing exposure and factors, having received free alcohol from a company representative was statistically significantly associated with drunkenness after controlling for demographic characteristics, psychosocial factors, high risk factors, and peer environment. Having received free alcohol remained significantly associated with drunkenness even in model 4 (AOR: $2.40 ; 95 \% \mathrm{CI}=1.22-4.70$ ) which also controlled for alcohol education. Alcohol education was not found to be a significant factor related to drunkenness (Table 3).

The same set of models was also computed for problem drinking (Table 4). Again, age $(\geq 18)$ was the most consistent correlate of problem drinking across the four models computed. In Models 2 through 4, drug use was also strongly associated with problem drinking. In Model 3 , which examined the potential role of alcohol marketing factors and exposure, having received free alcohol from a company representative was statistically significantly associated with problem drinking after controlling for demographic 
TABLE 3: Multivariate logistic regression analyses of the associations between demographic characteristics, alcohol marketing, and alcohol education and drunkenness among participants in the Kampala Youth Survey $(N=457)$.

\begin{tabular}{|c|c|c|c|c|}
\hline & & Four models pr & ng drunkenness & \\
\hline & Model 1 & Model 2 & Model 3 & Model 4 \\
\hline & AOR $(95 \% \mathrm{CI})$ & $\operatorname{AOR}(95 \% \mathrm{CI})$ & $\operatorname{AOR}(95 \% \mathrm{CI})$ & $\operatorname{AOR}(95 \% \mathrm{CI})$ \\
\hline Boys & $2.31(1.45-3.69)$ & $1.16(0.63-2.15)$ & $0.82(0.42-1.61)$ & $0.83(0.42-1.65)$ \\
\hline Girls & 1.00 & 1.00 & 1.00 & 1.00 \\
\hline Age $\geq 18$ & $2.89(1.76-4.74)$ & $2.49(1.34-4.61)$ & $2.06(1.09-3.90)$ & $1.99(1.05-3.74)$ \\
\hline Age $<18$ & 1.00 & 1.00 & 1.00 & 1.00 \\
\hline Sadness & - & $1.33(0.66-2.71)$ & $1.29(0.62-2.72)$ & $1.34(0.65-2.79)$ \\
\hline No friends & - & $0.17(0.04-0.74)$ & $0.27(0.06-1.21)$ & $0.25(0.05-1.16)$ \\
\hline Drug use & - & $10.77(5.62-20.66)$ & $8.20(4.06-16.55)$ & $9.04(4.37-18.71)$ \\
\hline Violence victimization & & $2.17(1.17-4.04)$ & $1.59(0.82-3.09)$ & $1.58(0.81-3.08)$ \\
\hline HIV/AIDS & & $3.10(1.32-7.28)$ & $2.16(0.89-5.25)$ & $2.36(0.94-5.92)$ \\
\hline Alcohol use and marketing exposure & - & & & \\
\hline $0-4$ & - & - & 1.00 & 1.00 \\
\hline $5-6$ & - & - & $2.00(0.94-4.22)$ & $2.08(1.01-4.24)$ \\
\hline Alcohol marketing & - & - & & \\
\hline Free drink & - & - & $2.34(1.18-4.62)$ & $2.40(1.22-4.70)$ \\
\hline Brand logo & & & $1.72(0.86-3.44)$ & $1.79(0.88-3.62)$ \\
\hline Alcohol education & - & - & - & \\
\hline Danger of alcohol & - & - & - & $0.52(0.18-1.48)$ \\
\hline Help quit & - & - & - & $1.31(0.58-2.96)$ \\
\hline Refuse alcohol & - & 一 & 一 & $1.27(0.58-2.76)$ \\
\hline
\end{tabular}

Each model included all listed variables. Reference categories for each variable are not shown but were those not exposed to or who did not report sadness, having no friends, drug use, violence victimization, alcohol marketing, or alcohol education.

TABLE 4: Multivariate logistic regression analyses of the associations between demographic characteristics, alcohol marketing, and alcohol education and problem drinking among participants in the Kampala Youth Survey $(N=457)$.

\begin{tabular}{|c|c|c|c|c|}
\hline & \multicolumn{4}{|c|}{ Four models predicting problem drinking } \\
\hline & Model 1 & Model 2 & Model 3 & Model 4 \\
\hline & $\operatorname{AOR}(95 \% \mathrm{CI})$ & AOR (95\% CI) & AOR (95\% CI) & $\operatorname{AOR}(95 \% \mathrm{CI})$ \\
\hline Boys & $2.33(1.44-3.77)$ & $1.16(0.61-2.19)$ & $0.85(0.43-1.71)$ & $0.85(0.42-1.70)$ \\
\hline Girls & 1.00 & 1.00 & 1.00 & 1.00 \\
\hline Age $\geq 18$ & $3.70(2.18-6.29)$ & $3.50(1.82-6.76)$ & $2.94(1.49-5.80)$ & $2.76(1.41-5.41)$ \\
\hline Age $<18$ & 1.00 & 1.00 & 1.00 & 1.00 \\
\hline Sadness & - & $1.72(0.79-3.73)$ & $1.76(0.78-3.95)$ & $1.89(0.85-4.21)$ \\
\hline No friends & - & $0.19(0.04-0.85)$ & $0.30(0.07-1.35)$ & $0.26(0.06-1.22)$ \\
\hline Drug use & - & $9.17(4.80-17.51)$ & $6.67(3.38-13.16)$ & $7.29(3.62-14.69)$ \\
\hline Violence victimization & & $2.35(1.24-4.42)$ & $1.70(0.85-3.41)$ & $1.67(0.83-3.35)$ \\
\hline HIV/AIDS & & $4.01(1.64-9.78)$ & $2.92(1.16-7.37)$ & $3.44(1.33-8.91)$ \\
\hline Alcohol use and marketing exposure & - & - & & \\
\hline $0-4$ & - & - & 1.00 & 1.00 \\
\hline $5-6$ & - & - & $1.17(0.54-2.51)$ & $1.17(0.55-2.47)$ \\
\hline Alcohol marketing & - & - & & \\
\hline Free drink & - & - & $2.40(1.18-4.88)$ & $2.47(1.23-4.96)$ \\
\hline Brand logo & & & $1.91(0.95-3.84)$ & $1.98(0.97-4.03)$ \\
\hline Alcohol education & - & - & - & \\
\hline Danger of alcohol & - & - & - & $0.63(0.22-1.76)$ \\
\hline Help quit & - & - & - & $0.75(0.35-1.62)$ \\
\hline Refuse alcohol & - & - & - & $1.66(0.82-3.37)$ \\
\hline
\end{tabular}

Each model included all listed variables. Reference categories for each variable are not shown but were those not exposed to or who did not report sadness, having no friends, drug use, violence victimization, alcohol marketing, or alcohol education. 
characteristics, risky behavior, and alcohol education. Having received free alcohol remained significantly associated with problem drinking even in Model 4 (AOR: 2.47 ; 95\% CI $=1.23-$ 4.96) which also controlled for alcohol education.

\section{Discussion}

This study examined the prevalence of exposure to alcohol education and alcohol marketing practices among slum and street youth in Kampala, Uganda. The findings show that many youth have received alcohol education; $89 \%$ of youth said they had been taught about the dangers of alcohol, $72 \%$ reported that they had been told where to get help to stop drinking alcohol, and $75 \%$ reported that they were taught how to refuse an alcoholic drink. These findings are very encouraging given that most of these youth are not attending school and may receive services and education primarily through nongovernmental organizations (NGOs) like UYDEL.

With respect to alcohol marketing exposure, $62 \%$ of youth reported exposure to 5-6 types of alcohol marketing, $26 \%$ reported having a t-shirt, pen backpack, or other alcohol brand logo item, and $27 \%$ reported that they had been offered a free drink through an alcohol company representative. These numbers are very high when considering the dire backgrounds and context of these youth, their limited belongings, and lifestyles. These findings clearly demonstrate that many of these youth are exposed to alcohol marketing and even offered free alcohol as a marketing strategy, which is of grave concern given that these youth are as young as 14 years of age.

Another goal of the study was to determine the extent to which alcohol education and alcohol marketing strategies were potentially inversely associated with current alcohol use, drunkenness, and problem drinking. The analyses show that knowing how to refuse alcohol reduced the likelihood of reporting current alcohol use but that exposure to alcohol marketing strategies, receiving free alcohol, and owning brand logo items were highly associated with current alcohol use. Similarly, exposure to a range of alcohol marketing exposures, receiving free alcohol, and also owning alcohol logo items also increased risk of reporting problem drinking and drunkenness.

Multivariate analyses that examined the correlates of drunkenness show that receiving free alcohol was the most important factor of all the alcohol variables examined, and this factor was also associated with problem drinking. Surprisingly, receiving alcohol education regarding the dangers of alcohol, knowing where to get help to quit, and knowing how to refuse alcohol when given were not statistically associated with either drunkenness or problem drinking in multivariate analyses. These findings, while preliminary, indicate that the development of new strategies is likely needed to counteract the effects of alcohol marketing and prevent and reduce levels of alcohol use and associated adverse outcomes through other strategies than education. Previous research shows that direct marketing of alcohol products is associated with alcohol use and problems among schoolattending youth [26] and those findings are corroborated by the findings in the current study of vulnerable youth, living in the slums of Kampala. These findings are also supported by research that shows that distributing alcohol merchandise to youth predicts their alcohol use [44]. And, more importantly, as found in previous research with students in Zambia [26], alcohol education did not lessen the association between alcohol marketing and drunkenness or problem drinking indicating that these marketing strategies are very robust. However, it is also important to recognize that these findings may be related to the limited context of alcohol education in these youths' home environment, given parental guidance has been found as a significant direct and indirect factor that lessens influences of alcohol advertisement and decrease alcohol use [44].

The results of this study should be viewed in the context of several important limitations. First, the study participants were not randomly selected, but were youth who self-selected to attend the drop-in centers and to take part of the study. Therefore, the findings may not be representative of street and slum youth in Kampala and may not be generalizable to populations elsewhere. However, the high response rate in the targeted drop-in centers increases our confidence that the findings are representative of the youth who self-select to attend drop-in centers or to seek services more generally. Second, the sample included both street youth who were homeless and youth who lived in the slums but may have had a stable living arrangement. Accordingly, our definition youth who live in the slums was broad and included a range of circumstances and family contexts (e.g., some of these youth currently lived with two caretakers or in a treatment setting and were relatively well fed and cared for) although circumstances varied significantly. If the study had only included homeless street youth, or if we had been able to differentiate these groups better, the prevalence of the health risk behavior as well as problem drinking and drunkenness may have been significantly higher among homeless street youth specifically. However, all youth who participated in the survey were help-seeking youth in that they had participated in services or training classes provided by the UYDEL which may also indicate that these youth are not representative of street youth more broadly and may also at least partially explain why our study included mostly girls. One of the most frequently offered training class by the centers was hairdressing and braiding which is likely to be attended by girls.

Third, because of limited literacy rates, participants was read the questionnaire. The face-to-face interaction between participant and interviewer may have resulted in underreporting of certain high-risk behavior associated with significant stigma. While this is an important potential concern because participants (who knew the interviewers) may have been unwilling to disclose sensitive information, it is less likely since the participants selected to attend the drop-in centers and discussions of sensitive information was part of many of the services provided. Fourth, during the interviews, participants often provided the answers in Luganda which required the interviewers to translate the response to English and make the appropriate notations on the questionnaire. This issue was anticipated and discussed during the training 
of the interviewers and appeared to have been handled appropriately during the data collection by the interviewers who were all proficient and fluent in both spoken and written English.

Fifth, most of the questions regarding high-risk behavior were selected from previously established self-administered surveys, particularly the Youth Risk Behavior Survey [42] conducted in USA, and also the Global School-Based Student Health Survey [43] conducted primarily in Africa, Asia, and Latin America. In several cases, the wording of the questions used was simplified and the response options narrowed in order to facilitate the administration of the survey questionnaires by the interviewers. As such, the reliability and validity of some of the measures may have been altered. Sixth, because of the cross-sectional nature of the survey, the temporal ordering of the risk factors and drunkenness and problem drinking cannot be determined, nor can causation be inferred.

The findings of this study show that at least one of the examined alcohol marketing efforts in Uganda, providing free alcohol to youth, appears to be strongly associated with current alcohol use, problem drinking, and drunkenness even after considering other important factors related to alcohol use. These alcohol marketing practices, aimed directly to children, have been banned in other countries and have important policy implications for countries where such bans do not exist. In Uganda, concerns have been expressed to underscore the ethical violations of alcohol companies which market and target their products directly to children [45]. The implications of the findings presented in this paper and from previous studies [26] are that stricter policies to prevent underage alcohol advertisements are needed. WHO has taken an important leadership role related to underage drinking and presented the global strategy to reduce the harmful use of alcohol [13] which recommends mandatory as well as voluntary regulations of marketing of alcohol products that need to be considered and included in a comprehensive strategy to reduce the harmful use of alcohol. The report also underscores that these measures need to be urgently considered and applied given the frequency and levels of exposure to alcohol marketing.

It is clear that the timing is critical for new policy initiatives and prevention strategies aimed to reduce alcohol use [46], in particular in Uganda. Earlier reports by the alcohol industry, as reported previously [26], indicate that they will produce and sell cheaper alcohol to African population in order to increase its consumer market [47]. Moreover, a report in BusinessWeek [47] noted that SABMiller, the world's second largest brewer, is exploring the "relatively untapped African market" to drive future growth, sales, and profits, which is estimated to be worth more than $\$ 3$ billion. Strategically, the goal of targeting low-income consumers and creating affordable brews will be achieved through using local ingredients such as cassava and barley, and also utilizing inexpensive individual sized packaging to make purchasing alcohol more affordable [47]. In Zambia, bans have already been implemented against the manufacturing and sale of strong liquor individual- sized sachets sold at very low prices, often in unlicensed bars and to minors [48]. Moreover, a recent commentary recommends that there should be a total ban on alcohol advertising in South Africa [49].

In terms of clinical practice and service provision, the findings from the current study underscore the ease by which youth appear to obtain alcohol and that the prevalence of drunkenness and problem drinking is high among these youth. Accordingly, there may be models for brief alcohol screening interventions that have been found very effective in USA, such as the electronic screening and brief intervention (e-SBI) recommended by the Guide to Community Preventive Services [50] that can be adapted for implementation among these service-seeking youth. In these settings, evidence-based interventions that can be delivered by lay workers and with minimal costs are needed to address problem drinking and drunkenness before youth become addicted to alcohol and before they experience other adverse alcohol-related outcomes such as injury and HIV.

\section{Acknowledgments}

The authors thank the Graduate Research Assistant, Huang Yao (who was formerly part of Dr. Swahn's research team), for her contribution to the analyses. Moreover, the team acknowledges the funding obtained from the Office of International Initiatives at Georgia State University to conduct the cross-sectional survey. The authors have no conflict of interests to disclose. The study protocol was approved by the Georgia State University Institutional Review Board and also by the Uganda National Council for Science and Technology. Funding to conduct the study was obtained from the Georgia State University Office of International Initiatives and also from funds leveraged through collaboration with the Emory Center for Injury Control, funded by the Centers for Disease Control and Prevention.

\section{References}

[1] J. Rehm, C. Mathers, S. Popova, M. Thavorncharoensap, Y. Teerawattananon, and J. Patra, "Global burden of disease and injury and economic cost attributable to alcohol use and alcohol-use disorders," The Lancet, vol. 373, no. 9682, pp. 22232233, 2009.

[2] World Health Organization, "Global status report on alcohol and health," 2011, http://www.who.int/substance_abuse/ publications/global_alcohol_report/msbgsruprofiles.pdf.

[3] R. W. Hingson, T. Heeren, and M. R. Winter, "Age at drinking onset and alcohol dependence: age at onset, duration, and severity," Archives of Pediatrics and Adolescent Medicine, vol. 160, no. 7, pp. 739-746, 2006.

[4] P. L. Ellickson, J. S. Tucker, and D. J. Klein, "Ten-year prospective study of public health problems associated with early drinking," Pediatrics, vol. 111, no. 5, pp. 949-955, 2003.

[5] R. W. Hingson, T. Heeren, A. Jamanka, and J. Howland, "Age of drinking onset and unintentional injury involvement after drinking," Journal of the American Medical Association, vol. 284, no. 12, pp. 1527-1533, 2000.

[6] R. Hingson, T. Heeren, R. Zakocs, M. Winter, and H. Wechsler, "Age of first intoxication, heavy drinking, driving after drinking and risk of unintentional injury among U.S. college students," Journal of Studies on Alcohol, vol. 64, no. 1, pp. 23-31, 2003. 
[7] R. Hingson, T. Heeren, and R. Zakocs, "Age of drinking onset and involvement in physical fights after drinking," Pediatrics, vol. 108, no. 4, pp. 872-877, 2001.

[8] H. Cho, D. D. Hallfors, and B. J. Iritani, "Early initiation of substance use and subsequent risk factors related to suicide among urban high school students," Addictive Behaviors, vol. 32, no. 8, pp. 1628-1639, 2007.

[9] M. H. Swahn, R. M. Bossarte, and E. E. Sullivent, "Age of alcohol use initiation, suicidal behavior, and peer and dating violence victimization and perpetration among high-risk, seventh-grade adolescents," Pediatrics, vol. 121, no. 2, pp. 297-305, 2008.

[10] M. H. Swahn and R. M. Bossarte, "Gender, early alcohol use, and suicide ideation and attempts: findings from the 2005 youth risk behavior survey," Journal of Adolescent Health, vol. 41, no. 2, pp. 175-181, 2007.

[11] D. Baliunas, J. Rehm, H. Irving, and P. Shuper, "Alcohol consumption and risk of incident human immunodeficiency virus infection: a meta-analysis," International Journal of Public Health, vol. 55, no. 3, pp. 159-166, 2010.

[12] J. C. Fisher, "Can we engage the alcohol industry to help combat sexually transmitted disease?" International Journal of Public Health, vol. 55, no. 3, pp. 147-148, 2010.

[13] World Health Organization, "Global strategy to reduce the harmful use of alcohol," 2010, http://www.who.int/substanceabuse/msbalcstragegy.pdf.

[14] M. H. Swahn, B. Ali, J. Palmier et al., "Early alcohol use and problem drinking among students in Zambia and Uganda," Journal of Public Health in Africa, vol. 2, no. 2, pp. e20-e23, 2011.

[15] M. E. Coldiron, R. Stephenson, E. Chomba et al., "The relationship between alcohol consumption and unprotected sex among known HIV-discordant couples in rwanda and Zambia," AIDS and Behavior, vol. 12, no. 4, pp. 594-603, 2008.

[16] S. C. Kalichman, L. C. Simbayi, M. Kaufman, D. Cain, and S. Jooste, "Alcohol use and sexual risks for HIV/AIDS in sub-saharan Africa: systematic review of empirical findings," Prevention Science, vol. 8, no. 2, pp. 141-151, 2007.

[17] S. Siziya, A. S. Muula, L. N. Kazembe, and E. Rudatsikira, "Harmful lifestyles' clustering among sexually active in-school adolescents in Zambia," BMC Pediatrics, vol. 8, article 6, 2008.

[18] S. D. Weiser, K. Leiter, M. Heisler et al., "A population-based study on alcohol and high-risk sexual behaviors in Botswana," PLoS Medicine, vol. 3, no. 10, Article ID e392, pp. 1940-1948, 2006.

[19] J. Mayeya, R. Chazulwa, P. N. Mayeya et al., "Zambia mental health country profile," International Review of Psychiatry, vol. 16, no. 1-2, pp. 63-72, 2004.

[20] S. Hassan, W. M. Macharia, and J. Atinga, "Self reported alcohol use in an urban traffic trauma population in Kenya," East African Medical Journal, vol. 82, no. 3, pp. 144-147, 2005.

[21] P. L. Ellickson, R. L. Collins, K. Hambarsoomians, and D. F. McCaffrey, "Does alcohol advertising promote adolescent drinking? Results from a longitudinal assessment," Addiction, vol. 100, no. 2, pp. 235-246, 2005.

[22] S. Q. Hurtz, L. Henriksen, Y. Wang, E. C. Feighery, and S. P. Fortmenn, "The relationship between exposure to alcohol advertising in stores, owning alcohol promotional items, and adolescent alcohol use," Alcohol and Alcoholism, vol. 42, no. 2, pp. 143-149, 2007.

[23] A. C. McClure, S. Dal Cin, J. Gibson, and J. D. Sargent, "Ownership of alcohol-branded merchandise and initiation of teen drinking," American Journal of Preventive Medicine, vol. 30, no. 4, pp. 277-283, 2006.
[24] L. B. Snyder, F. F. Milici, M. Slater, H. Sun, and Y. Strizhakova, "Effects of alcohol advertising exposure on drinking among youth," Archives of Pediatrics and AdolescentMedicine, vol. 160, no. 1, pp. 18-24, 2006.

[25] S. Vantamay, "Alcohol consumption among university students: applying a social ecological approach for multi-level preventions," Southeast Asian Journal of Tropical Medicine and Public Health, vol. 40, no. 2, pp. 354-369, 2009.

[26] M. H. Swahn, B. Ali, J. B. Palmier, G. Sikazwe, and J. Mayeya, "Alcohol marketing, drunkenness, and problem drinking among zambian youth: findings from the 2004 global schoolbased student health survey," Journal of Environmental and Public Health, vol. 2011, Article ID 497827, 8 pages, 2011.

[27] M. H. Swahn, R. M. Bossarte, D. M. Elimam, E. Gaylor, and S. Jayaraman, "Prevalence and correlates of suicidal ideation and physical fighting: a comparison between students in Botswana, Kenya, Uganda, Zambia and the USA," International Journal of Public Health, vol. 2, no. 2, pp. 195-206, 2010.

[28] World Health Organization, "Monitoring alcohol marketing in Africa: MAMPA Project," 2011, http://www.afro.who.int/en/ clusters-a-programmes/hpr/health-risk-factors/diseases-surveillance/highlights3032-monitoring-alcohol-marketing-infrica.html.

[29] P. Anderson, D. Chisholm, and D. C. Fuhr, "Effectiveness and cost-effectiveness of policies and programmes to reduce the harm caused by alcohol," The Lancet, vol. 373, no. 9682, pp. 2234-2246, 2009.

[30] K. Fleming, E. Thorson, and C. K. Atkin, "Alcohol advertising exposure and perceptions: links with alcohol expectancies and intentions to drink or drinking in underaged youth and young adults," Journal of Health Communication, vol. 9, no. 1, pp. 3-29, 2004.

[31] A. Wyllie, J. F. Zhang, and S. Casswell, "Positive responses to televised beer advertisements associated with drinking and problems reported by 18 to 29-year-olds," Addiction, vol. 93, no. 5, pp. 749-760, 1998.

[32] N. O. A. Kwate and I. H. Meyer, "Association between residential exposure to outdoor alcohol advertising and problem drinking among African American Women in New York City," American Journal of Public Health, vol. 99, no. 2, pp. 228-230, 2009.

[33] J. B. Unger, C. A. Johnson, and L. A. Rohrbach, "Recognition and liking of tobacco and alcohol advertisements among adolescents: relationships with susceptibility to substance use," Preventive Medicine, vol. 24, no. 5, pp. 461-466, 1995.

[34] K. E. Pasch, K. A. Komro, C. L. Perry, M. O. Hearst, and K. Farbakhsh, "Outdoor alcohol advertising near schools: what does it advertise and how is it related to intentions and use of alcohol among young adolescents?" Journal of Studies on Alcohol and Drugs, vol. 68, no. 4, pp. 587-596, 2007.

[35] D. Jernigan, Global Status Report: Alcohol and Young People, World Health Organization, Geneva, Switzerland, 2001, http://whqlibdoc.who.int/hq/2001/who_msd_msb_01.1.pdf.

[36] D. Jernigan, I. Obot, and N. Jos, "Thirsting for the African market," African Journal of Drug and Alcohol Studies, vol. 5, no. 1, pp. 57-70, 2006.

[37] D. H. Jernigan, "The extent of global alcohol marketing and its impact on youth," Contemporary Drug Problems, vol. 37, no. 1, p. $57,2010$.

[38] Alcohol Justice, “Tactics: Advertising and Promotion," 2012, http://alcoholjustice.org/big-alcohol/industry-tactics/24-tactic-advertising-and-promotions.html. 
[39] M. H. Swahn, J. B. Palmier, R. Kasirye, and H. Yao, "Correlates of suicide ideation and attempt among youth living in the slums of Kampal," International Journal of Environmental Research and Public Health, vol. 9, no. 2, pp. 596-609, 2012.

[40] M. H. Swahn, L. Gressard, J. B. Palmier, R. Kasirye, C. Lynch, and $\mathrm{H}$. Yao, "Serious violence victimization and perpetration among youth living in the slums of Kampala, Uganda," Western Journal of Emergency Medicine, vol. 13, no. 3, pp. 253-259, 2012.

[41] Uganda Youth Development Link, 2012, http://www.uydel.org/.

[42] Center for Disease Control and Prevention, "Youth Risk Behavior Surveillance System (YRBSS)," 2012, http://www.cdc.gov/ HealthyYouth/yrbs/index.htm/.

[43] Centers for Disease Control and Prevention (CDC), "Global School-based Student Health Survey," 2012, http://www.cdc .gov/GSHS/.

[44] E. W. Austin, M. J. Chen, and J. W. Grube, "How does alcohol advertising influence underage drinking? The role of desirability, identification and skepticism," Journal of Adolescent Health, vol. 38, no. 4, pp. 376-384, 2006.

[45] W. Ngwenya, "Advertising in Zambia-Who is Targeted?" Lusaka Times, 2009, http://www.lusakatimes.com/?p=17511.

[46] S. Casswell and T. Thamarangsi, "Reducing harm from alcohol: call to action," The Lancet, vol. 373, no. 9682, pp. 2247-2257, 2009.

[47] K. Capell, "SABMiller's plan for cheaper African beer," BusinessWeek, 2009, http://www.businessweek.com/globalbiz/ content/apr2009/gb2009048046722.htm.

[48] Zambian Government Bans Some Alcohol Sales, Zambia Reports, 2012, http://zambiareports.com/2012/04/16/zambiangovernment-bans-some-alcohol-sales/.

[49] C. Parry, N. H. Burnhams, and L. A. London, "A total ban on alcohol advertising: presenting the Public Health Case," South African Medical Journal, vol. 102, no. 7, pp. 602-604, 2012.

[50] Guide to Community Preventive Services, "Preventing excessive alcohol consumption: electronic screening and brief intervention (e-SBI)," 2012, http://www.thecommunityguide .org/alcohol/eSBI.html/. 


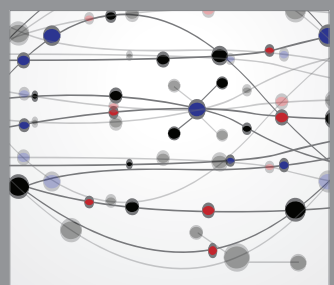

The Scientific World Journal
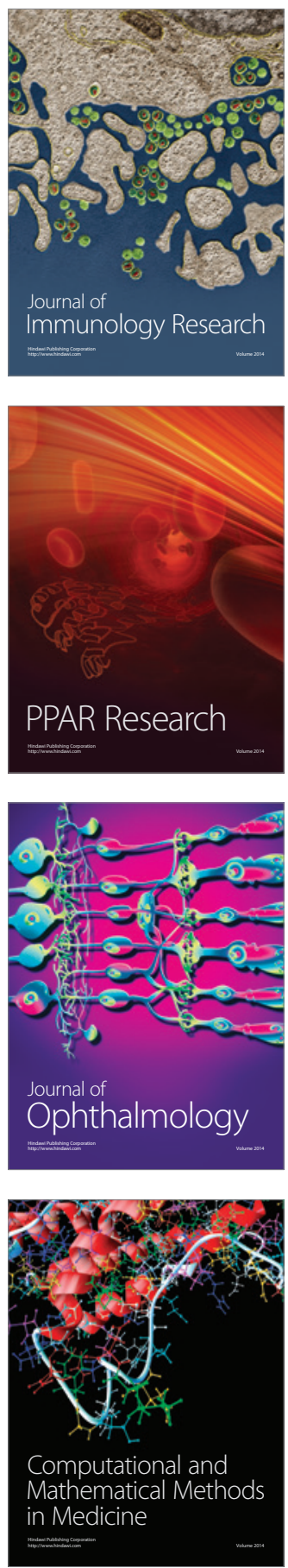

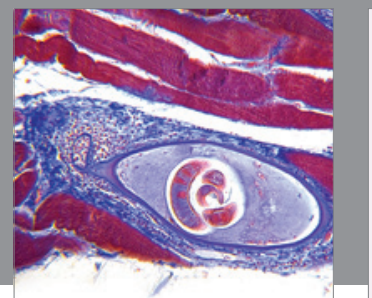

Gastroenterology

Research and Practice
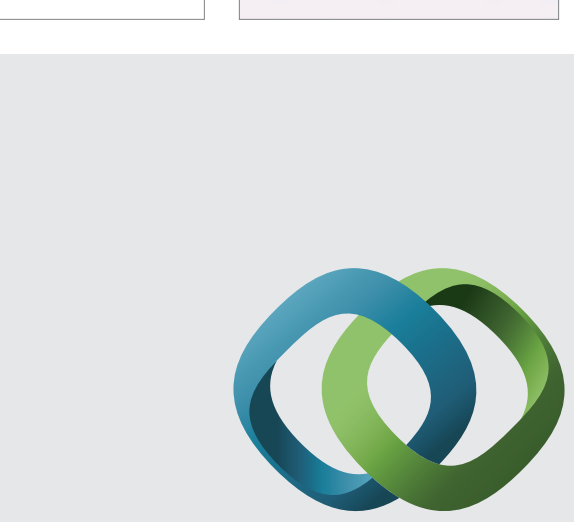

\section{Hindawi}

Submit your manuscripts at

http://www.hindawi.com
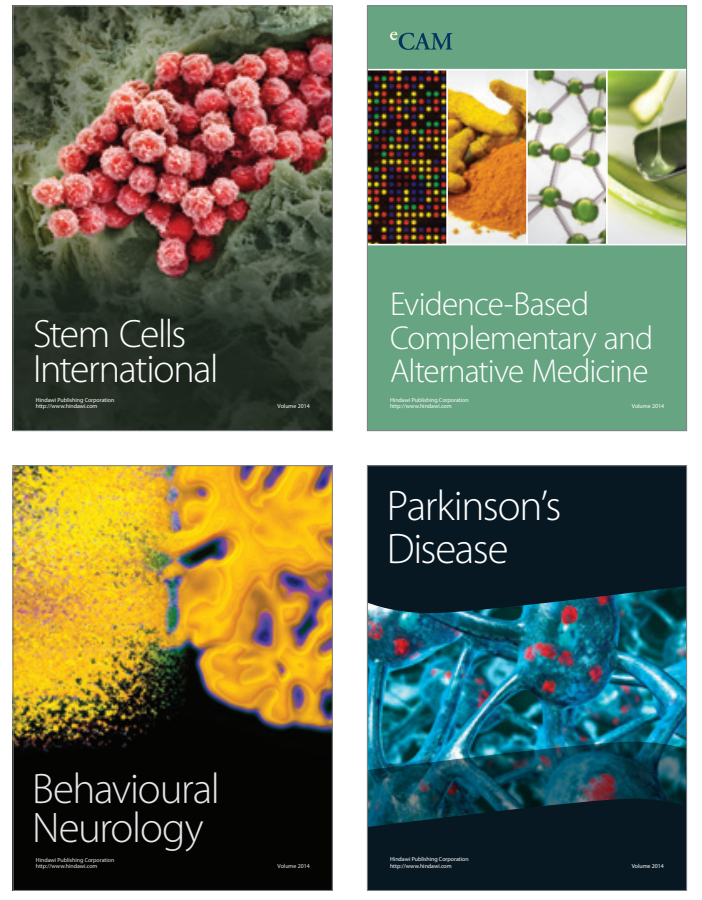
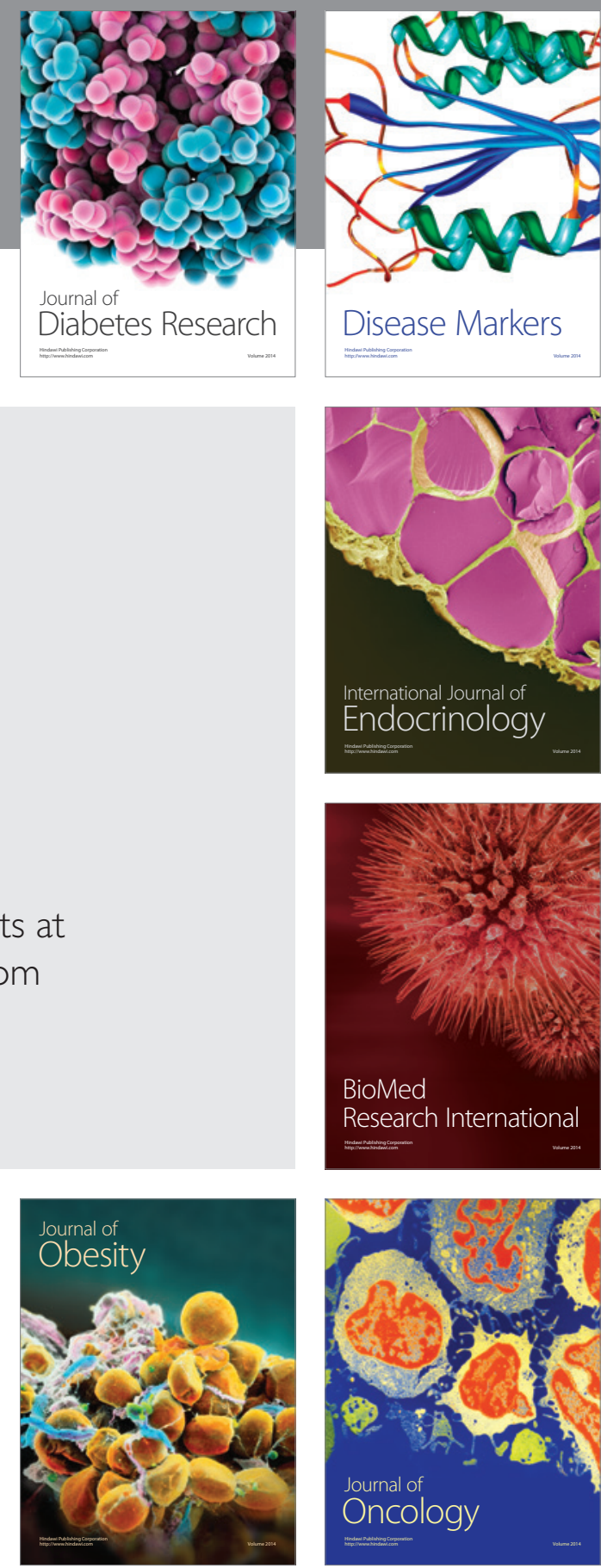

Disease Markers
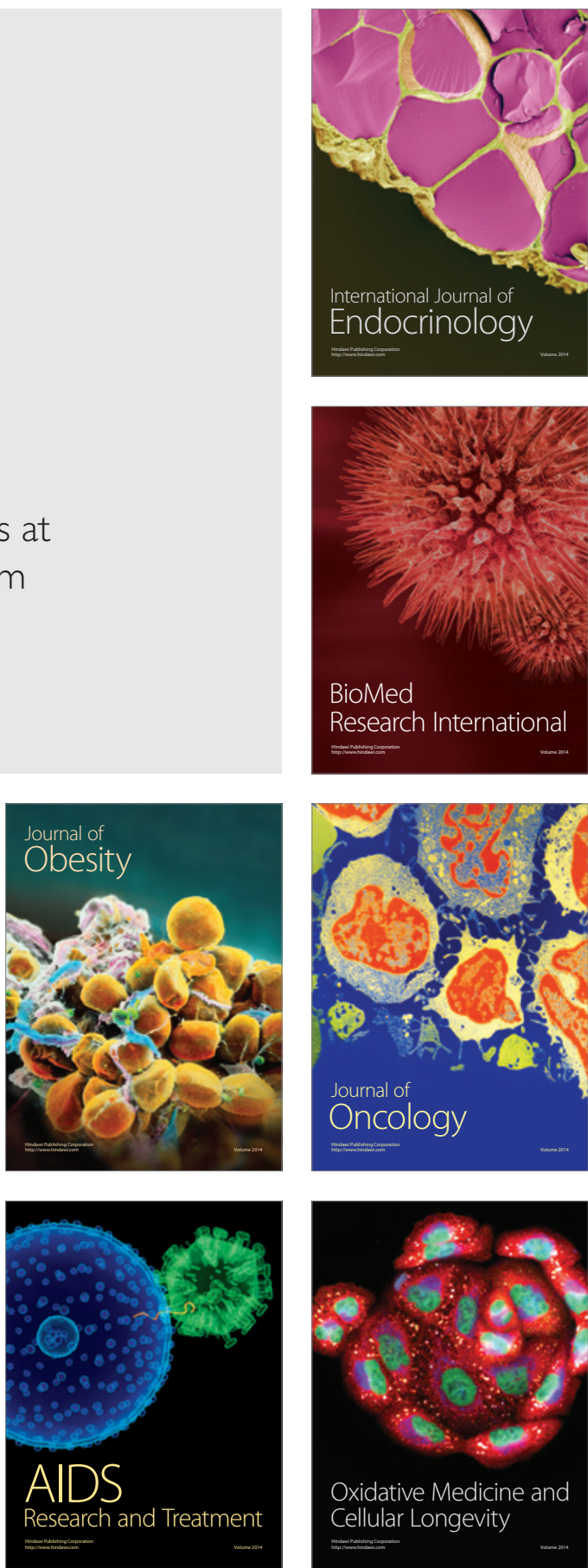